\title{
A geometric method to study water and sediment exchange in tidal harbors
}

\author{
Joris Vanlede • Arvid Dujardin
}

Received: 21 June 2012 / Accepted: 2 September 2014 / Published online: 24 September 2014

(C) The Author(s) 2014. This article is published with open access at Springerlink.com

\begin{abstract}
The exchange flow of water and sediment between a harbor and the surrounding waters can be geometrically decomposed into three main components: tidal filling, horizontal, and vertical exchange flows. The method is applied to analyze available measurements at two important harbor basins in Belgium. The geometric analysis can also be applied to the results of a numerical model of hydrodynamics and sediment transport, provided it has sufficient horizontal, vertical, and temporal resolutions to capture the dynamics at the harbor mouth. As such, it can be used as a tool in model calibration. The presented method can provide some insight into the complex relationship (phasing and spatial correlations) between hydrodynamics and sediment concentration that determines harbor siltation.
\end{abstract}

Keywords Harbor · Siltation · Exchange flow

\section{Introduction}

Many ports throughout the world suffer from significant siltation, necessitating frequent maintenance in the form of dredging to safeguard navigation (Winterwerp 2005). In Belgium,

Responsible Editor: Qing He

This article is part of the Topical Collection on the 11th International Conference on Cohesive Sediment Transport

J. Vanlede $\cdot$ A. Dujardin

Flanders Hydraulics Research, Antwerp, Belgium

J. Vanlede $(\square)$

Faculty of Civil Engineering and Geosciences, Delft University of

Technology, Delft, The Netherlands

e-mail: joris.vanlede@mow.vlaanderen.be

A. Dujardin

Antea Group, Ghent, Belgium the Flemish government is responsible for maintaining the maritime access to the ports of Antwerp and Zeebrugge. For more than a decade, it has invested in measurement campaigns and numerical model studies to gain more insight in the processes that drive the siltation in those harbors.

Three main flow mechanisms induce an exchange of water across the interface between a harbor and the surrounding waters under tidal influence (Eysink 1989; Langendoen 1992; Winterwerp 2005; PIANC 2008):

1. Exchange flow across the interface between the flow outside the harbor and shear-induced circulation inside the harbor.

2. Exchange flow by tidal filling.

3. Exchange flow driven by a density difference inside and outside the harbor. This density difference can be driven by a horizontal gradient in salinity, temperature, or sediment concentration.

In addition to the different components of the water exchange, the siltation of a harbor will also depend on the relationship between the water exchange and suspended sediment concentration (de Nijs et al. 2009 and van Maren et al. 2009). Despite the obvious relevance because of highmaintenance dredging costs, the relation between exchange mechanisms and harbor siltation is still poorly understood. Even with the continuously improving computer models, detailed numerical model studies on exchange flows and siltation in harbor basins are limited (Langendoen 1992; Stoschek and Zimmerman 2006; van Maren et al. 2009). When studying harbor siltation with a numerical model, the model output will give total sediment fluxes due to the interaction of all processes that the modeler has included in the schematization. During model calibration and for the interpretation of the results, the modeler may benefit from techniques that separate the total sediment flux into separate components. 
This paper describes a simple geometric decomposition of the exchange flow and applies it on available measurements at two important harbor basins in Belgium.

\section{Method}

A large body of work already exists on the decomposition of mass transport. In the 1960s, 1970s, and 1980s, geometric decomposition of velocity, concentration, and cross-sectional area was used to investigate the relative importance of tidally averaged longitudinal mass transport phenomena in estuaries, first of salt and then extended to suspended sediments. Costa (1989) gives an overview in a unified notation of the different decomposition techniques that have been used over time.

The method presented in this paper is a flux decomposition of water and sediment exchange across a fixed interface at the entrance of a harbor basin during one tidal cycle. The flow normal to the interface is decomposed geometrically into three main components (tidal, horizontal, and vertical) and one residual component. The decomposed sediment flux is obtained by multiplying the decomposed flow with the concentrations at the interface. Total fluxes are obtained by integrating over one tidal cycle.

The use of a simple geometric decomposition to study mass fluxes is not new of course. Murray and Siripong (1978) also use a combination of vertical, horizontal, and cross-sectional averaging to decompose the flow and - separately-also the salinity in a study on salt fluxes in a shallow estuary. After averaging out over a tidal cycle, their decomposition of the mass flux has ten terms. The method presented in this paper is kept simpler in comparison. By choosing not to decompose the sediment concentration, the mass flux is decomposed in only four terms. Also, the tidal averaging is only done at the end, in order to study the intratidal variation of the mass flux.

\subsection{Decomposition of flow}

The exchange of water between a harbor of arbitrary shape and a tidal water body (e.g., the sea or a tidal river) is determined by the velocity field $\vec{v}(x, z, t)$ at the interface between the harbor and the connecting water body. This interface is indicated in gray in Fig. 1. The $x$-axis runs along the harbor entrance. The $z$-axis runs over the depth (positive upward).

The (scalar) velocity component perpendicular to the harbor entrance $v_{n}(x, z, t)$ is calculated with a dot product. $v_{n}$ is the only component that contributes to the exchange of water (and sediment) between the harbor and the connecting water body. $\overrightarrow{e_{n}}$ is the unit vector perpendicular to the harbor entrance, directed outwards.

$v_{n}=\vec{v} \cdot \vec{e}_{n}$
The scalar velocity $v_{n}$ is decomposed into three plus one components. Firstly, the cross-sectional average $v_{\text {tidal }}(t)$ is determined. $v_{\text {tidal }}$ is the net water exchange between the harbor and the connecting water body and is related to the water level in the harbor through a volume balance. It is depicted in Fig. 1a.

$v_{\text {tidal }}=\frac{\iint_{A} v_{n} d A}{A}$

The surface of the interface between the harbor and the connecting water body is denoted as $A$. The remainder $\widetilde{v}$ $(x, z, t)$ corresponds to the gross exchange of water without any net exchange:

$\widetilde{v}=v_{n}-v_{\text {tidal }}$

$\widetilde{v}$ can be geometrically split up in a horizontal component $v_{\text {hor }}(x, t)$ that has no variation over the vertical and a vertical component $v_{\mathrm{ver}}=(z, t)$ without any variation over the horizontal. Both components are calculated separately from $\widetilde{v}$ :

$v_{\text {hor }}(x, t)=\frac{\int_{H(x, t)} \widetilde{v}(x, z, t) d z}{H(x, t)}$

$v_{\mathrm{ver}}(z, t)=\frac{\int_{B(z, t)} \widetilde{v}(x, z, t) d x}{B(z, t)}$

$H(x, t)$ is the available water depth at every point along the entrance transect and $B(z, t)$ is the available width of the entrance transect at every depth.

$v_{\text {hor }} \cdot\left(v_{\text {ver }}\right)$ as calculated in Eqs. 4 and 5 is a 1-D horizontal (vertical) scalar and is expanded to the entire interface between the harbor and the connecting water body by repeating the 1-D scalar over the available depth (width). In the following paragraphs, $v_{\text {hor }}$ and $v_{\text {ver }}$ indicate the expanded 2-D scalar fields.

Finally, the residual component $v_{\mathrm{res}}=(x, z, t)$ is determined by Eq. 6.

$v_{n}=v_{\text {tidal }}+v_{\text {hor }}+v_{\text {ver }}+v_{\text {res }}$

By definition, the following relation holds:

$\iint_{A} \widetilde{v} d A=0$

Note that although $\widetilde{v}$ is the summation of $v_{\text {hor }} v_{\text {ver, }}$, and $v_{\text {res; }}$; it is only in rectangular cross sections that the cross-sectional integrals $\iint_{A} v_{\text {hor }} d A, \iint_{A} v_{\text {ver }} d A$, and $\iint_{A} v_{\text {res }} d A$ equal zero.

Note that $v_{\text {hor }}$ and $v_{\text {ver }}$ are determined separately from $\widetilde{v}$ (a parallel approach). One could argue to rather use a sequential 


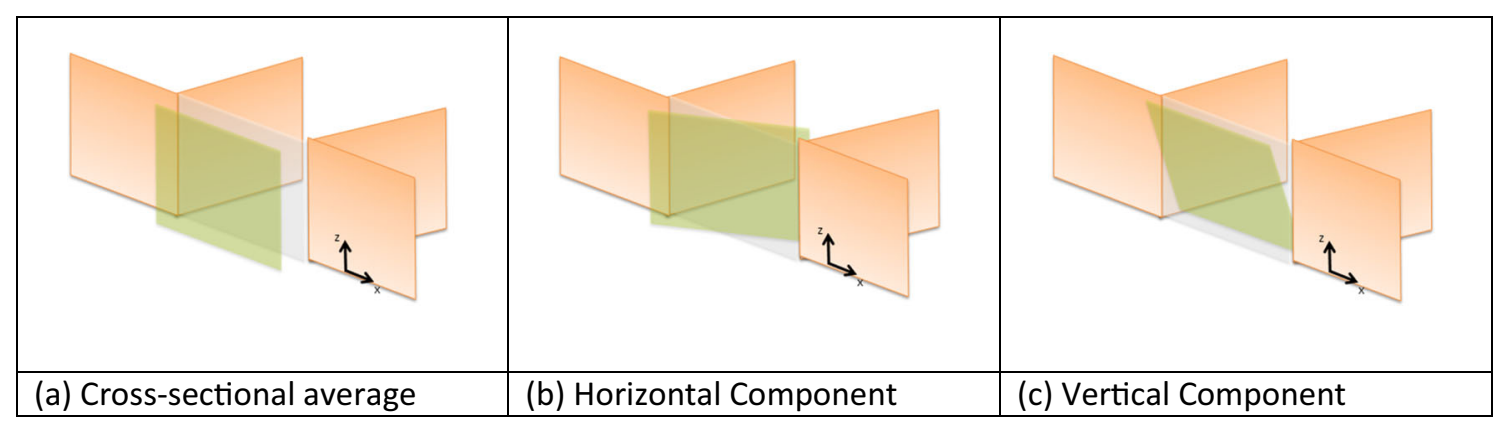

Fig. 1 Three major components of the exchange flow at a harbor mouth

approach and determine $v_{\mathrm{ver}}$ from the horizontal averaging of $\widetilde{v}-v_{\text {hor }}$, or the other way around, depending on which contribution is believed to be the most important from a physical understanding of the system. A sensitivity analysis on synthetic flow fields showed however that non-rectangular cross sections (which is usually the case in field conditions), leads to slightly larger values (order of magnitude of $1 \%$ ) of the cross-sectional integrals $\iint_{A} v_{\text {hor }} d A$ and $\iint_{A} v_{\text {ver }} d A$, which hampers the interpretation, because all net exchange should be caught in $v_{\text {tidal }}$.

\subsection{Integration over time: additional operators}

The instantaneous water flux $F^{\mathrm{wat}}(t)$ is defined as

$F^{\mathrm{wat}}=\iint_{A} v_{n} d A$

If only the positive or negative parts of a scalar field are integrated, this is indicated with a superscript plus or minus sign. For instance:

$F^{\text {wat }+}=\iint_{A} \max \left(O, v_{n}\right) d A$

The total flux over a tidal period is obtained by integrating over one tidal period $T$ and is denoted with a hat operator. For instance:

$\widehat{F}^{\text {wat }}=\int_{O}^{T} F^{\text {wat }} d t$

\subsection{Decomposition of the sediment flux}

The instantaneous sediment mass flux $F^{\mathrm{sed}}(t)$ is defined as

$F^{\mathrm{sed}}=\iint_{A} v_{n} c d A$

with $c(x, z, t)$ the mass concentration of sediment at the interface between the harbor and the connecting water body.
Equation 6 gives the decomposition of the scalar velocity field perpendicular to the harbor entrance $\left(v_{n}\right)$ into three plus one scalar velocity fields that are defined at the interface between the harbor and the connecting water body.

Combining Eqs. 6 and 11, one obtains the decomposition of the total instantaneous sediment mass flux $F^{\text {sed }}(t)$ into three plus one components.

As an example, the sediment flux $F_{\text {tidal }}^{\mathrm{sed}}(t)$, related to the tidal filling and emptying, is written as

$F_{\text {tidal }}^{\text {sed }}=\iint_{A} v_{\text {tidal }} c d A$

In a similar way as with the calculation of the water fluxes, one might only take into account the positive (outflowing) part of the scalar velocity in the calculation of the sediment flux:

$F_{\text {tidal }}^{\text {sed }}=\iint_{A} \max \left(0, v_{\text {tidal }}\right) c d A$

In a cyclical tide, $\widehat{F}_{\text {tidal }}^{\text {wat }}$ is zero (no net exchange of water). Note that even in a cyclical tide, $\widehat{F}_{\text {tidal }}^{\text {sed }}$ will generally not be zero, for there is generally a relation between the crosssectional average sediment concentration and the tidal phase.

The components $F$ hor, $F_{\text {ver }}^{\text {sed }}$, and $F$ res sed are calculated in the same way as $F$ tidal in Eq. 12 . This way, the decomposition of the instantaneous sediment flux $F^{\text {sed }}$ is obtained:

$F^{\text {sed }}=F_{\text {tidal }}^{\text {sed }}+F_{\text {hor }}^{\text {sed }}+F_{\text {ver }}^{\text {sed }} F_{\text {res }}^{\text {sed }}$

Evidently, a similar relation also holds for the total fluxes $\widehat{F}^{\text {sed }}, \widehat{F}^{\text {sed }+}$, and $\widehat{F}^{\text {sed- }}$.

Note that the decomposition of the instantaneous sediment flux, as derived in Eq. 14, combines synoptic observations of hydrodynamics and sediment concentration. That way, the spatial and temporal cross correlations between the water exchange and the sediment concentration are implicitly taken into account. 


\subsection{Possible applications}

The geometric decomposition of flow and sediment flux is diagnostic in nature and is meant to be applied to synoptic scalar fields of both perpendicular flow velocity and sediment concentration at the interface between a harbor and the surrounding waters. These synoptic scalar fields can be derived from measurements and/or model results.

A measurement technique particularly suited for this type of analysis is a sailed ADCP campaign (Acoustic Doppler Current Profiler) with a calibrated interpretation of the acoustic backscatter to determine the sediment concentration. This measurement technique can describe both hydrodynamics and sediment concentration with a high spatial and temporal resolutions on one transect over a tidal cycle. The ADCP is typically mounted amidships on a measurement vessel, looking vertically down to the bed. Because the measurement vessel always has to keep a safe distance from structures, there is always an unmeasured area nearshore. Furthermore, there is always a small unmeasured area close to the surface and close to the bottom due to limitations of the measurement technique. In the processing of the datasets for this paper, the missing values have been filled in using a nearest-neighbor extrapolation.

\section{Application to the Zeebrugge harbor}

\subsection{Situation}

The harbor of Zeebrugge is situated in the Belgian coastal zone (southern North Sea), close to the mouth of the Western Scheldt estuary, see Fig. 2. Its outer port is reclaimed from the sea and is protected from it by two breakwaters, each about $4 \mathrm{~km}$ in length. The harbor mouth is in open connection to the sea. The average tidal amplitude at Zeebrugge is $4 \mathrm{~m}$. The open water surface is $6 \times 10^{6} \mathrm{~m}^{2}$, which gives a tidal volume of $24 \times 10^{6} \mathrm{~m}^{3}$. The cross-sectional surface between the harbor and sea is about $12,000 \mathrm{~m}^{2}$.

The Belgian and southern Dutch coastal waters are an effective trap for fine-grained cohesive sediments, resulting in the formation of an area of high suspended particulate matter (SPM) concentration around the harbor of Zeebrugge, between Oostende, and the Western Scheldt estuary. Most of these suspended sediments originate from the English Channel and are transported into the North Sea through the Strait of Dover. In the high-turbidity area, the depth-averaged SPM concentrations of minimum $20-70 \mathrm{mg} / 1$ and maximum $100-600 \mathrm{mg} / \mathrm{l}$ have been measured (Fettweis and Van den Eynde 2003)

Over the period 2005-2007, on average, $36 \times 10^{5}$ tons dry matter (TDM)/year was dredged in the harbor of Zeebrugge every year and dumped on authorized dumping sites in the Belgian part of the North Sea (Lauwaert et al. 2008). This number includes maintenance dredging, but excludes capital dredging.

In 2007, a measurement campaign of flow, salinity, and sediment concentration at Zeebrugge was commissioned by Flanders Hydraulics Research. The measurement on 31 July 2007 consisted of 22 sailed transects at the entrance of the harbor of Zeebrugge, performed over one tidal cycle (a spring tide in the summer of 2007). During this campaign, water velocity and sediment concentration were measured using a 600-kHz Workhorse Acoustic Doppler Current Profiler (ADCP) with a calibrated interpretation of the acoustic backscatter to determine the sediment concentration. This calibration was performed by taking water samples during the measurement campaign (IMDC 2008). One sailed transect is typically $700 \mathrm{~m}$ in length and consists of 200 to 300 ensembles (vertical profiles). Each ensemble has a vertical resolution of $50 \mathrm{~cm}$. Figure 3 shows one transect, measured during flood tide. Flow velocity (left) and suspended sediment concentration (right) were measured at the same time. For the analysis,

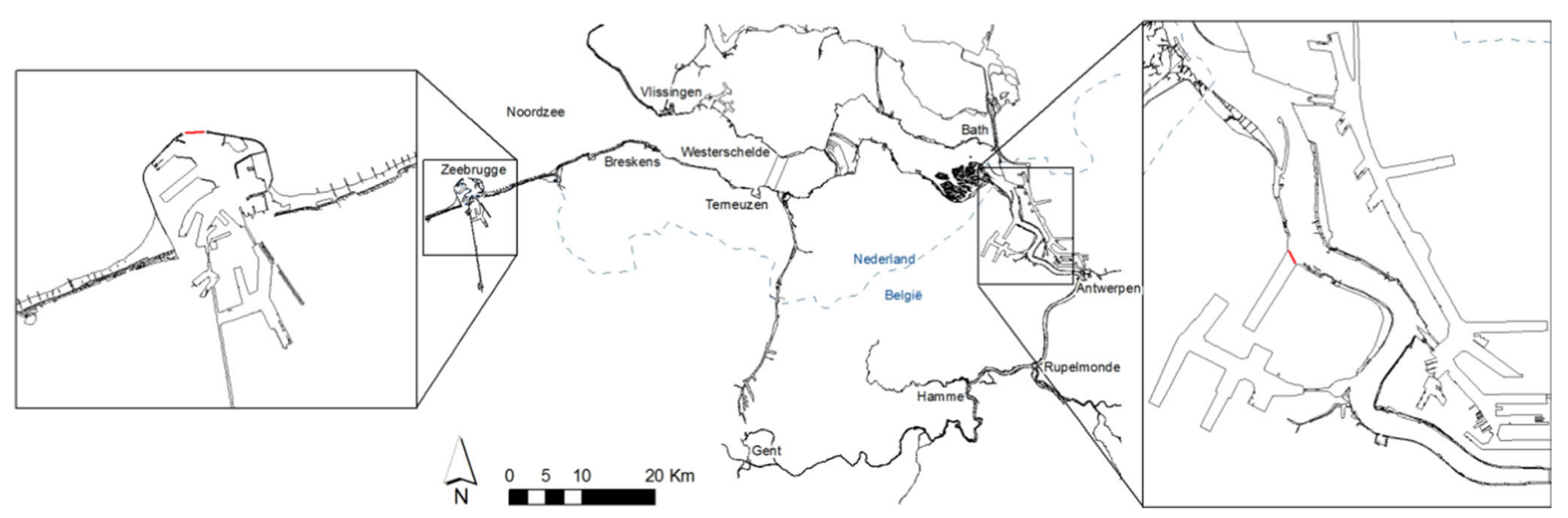

Fig. 2 Situation plan of Zeebrugge (left $)$ and of Deurganckdok (right) in the Scheldt estuary and the Belgian coastal zone. The measurement transects in both harbors are indicated in red 
the data is resampled on a regular grid of $1 \mathrm{~m} \times 1 \mathrm{~m}$. Seventyfour percent of the data points in the analysis are derived from measurements; $26 \%$ are filled in through nearest-neighbor extrapolation.

\subsection{Results and discussion}

The instantaneous flow field of Fig. 3 is geometrically decomposed following the method outlined above. The decomposed flow field is presented in Fig. 4.

The geometric decomposition shown in Fig. 4 is done for all 22 measured transects. For each component and for every transect, the instantaneous water and sediment flux are calculated. Figure 5 presents those calculated fluxes for all measured transects during the entirety of the measurement campaign, which spans one tidal cycle. The left-hand side of Fig. 5 shows the fluxes associated with the horizontal component of the flow. The tidal variation of $F$ hor wat $F$ hor can be seen in the top panel. $F_{\text {hor }}^{\text {wat }}$ is decomposed into $F_{\text {hor }}^{\text {wat }}$ and $F_{\text {hor }}^{\text {wat- }}$ in the second panel. The third panel shows the decomposition of $F$ hor into $F_{\text {hor }}^{\text {sed }}$ and $F$ hor hed The water level is added for reference in the bottom panel. The right-hand side of Fig. 5 shows the fluxes associated with the vertical component of the flow.

In general, the net sediment flux is directed inward (negative values for sediment flux in the top panel of Fig. 5). Table 1 gives the decomposition of the total sediment fluxes (integrated over one tidal period): $\widehat{F}^{\text {sed }}, \widehat{F}^{\text {sed }+}$, and $\widehat{F}^{\text {sed- }}$.

The values of the gross sediment exchange in Table 1 show that the horizontal exchange is the most important driver of the gross sediment exchange at the harbor mouth of Zeebrugge. The left panel in Fig. 5 shows that most horizontal sediment exchange happens from $2 \mathrm{~h}$ before high water to high water. Around that time, the flood flow in the North Sea (directed northeastward along the Belgian coast) drives a primary gyre in the harbor. The gyre is transported into the basin with the net tidal inflow. This results in water inflow concentrated towards the eastern breakwater and outflow towards the western breakwater. The combination of a gyre with tidal inflow is evident from the measured velocity field in Fig. 3, and its decomposition is shown in Fig. 4. Because of sediment settling in the harbor, the sediment concentration in the outflowing water is lower than that in the inflowing water.

The gross vertical water exchange however is only half as important as the gross horizontal water exchange (Fig. 5, second panel from the top). The density difference inside and outside the harbor seems to be too small to trigger an important density-driven exchange flow.

The difference between horizontally and vertically driven sediment exchanges is less apparent for the net sediment import to the Zeebrugge harbor (see Table 1). This could be related to the limits in accuracy when calculating a relatively small net value by subtracting two relatively large positive and negative contributions.

A net import of 708 TDM during one tidal cycle in July 2007 is lower than what would be expected from the dredging statistics mentioned earlier. One tidal cycle is not representative however for the average conditions over a longer period, so care should be taken when extrapolating the results of one tidal cycle. Furthermore, the analyzed tidal cycle was measured in summer conditions, when SPM concentrations in the North Sea are generally lower (Fettweis and Nechad 2011).

\section{Application to Deurganckdok}

\subsection{Situation}

Deurganckdok is a tidal dock in the port of Antwerp, on the left bank of the Lower Sea Scheldt, which is the stretch of the Scheldt estuary between the Belgium-Dutch border and Rupelmonde (see Fig. 2). The connection between the dock and the estuary was opened in 2005. In contrast to preexisting docks in the port of Antwerp, in which ships enter through locks, the entrance of Deurganckdok has an open connection to the Lower Sea Scheldt. This part of the Scheldt is
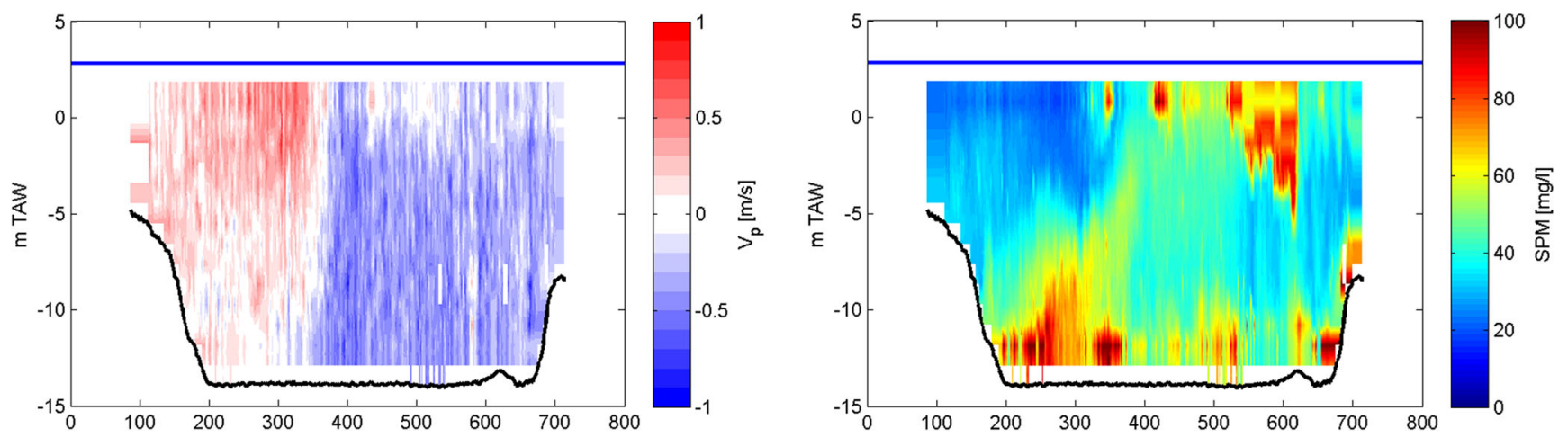

Fig. 3 Measured perpendicular flow (left panel) and suspended sediment concentration (right panel). The measurement was performed at the entrance of the harbor of Zeebrugge during flood phase 

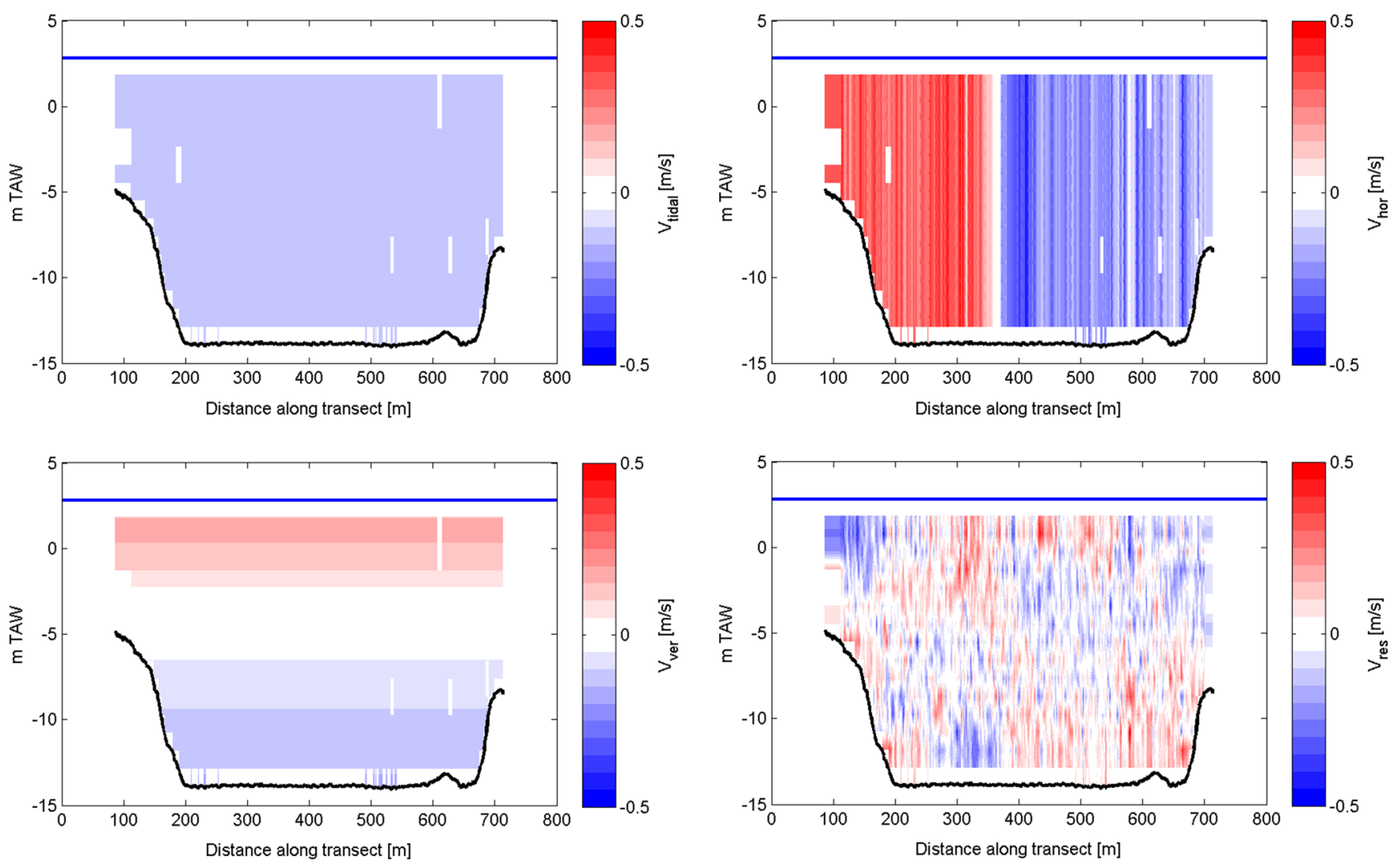

Fig. 4 Result of the geometric decomposition of one measured flow transect at the entrance of the harbor of Zeebrugge (see Fig. 3). The tidal component (or cross-sectional average) is shown in the top left, the

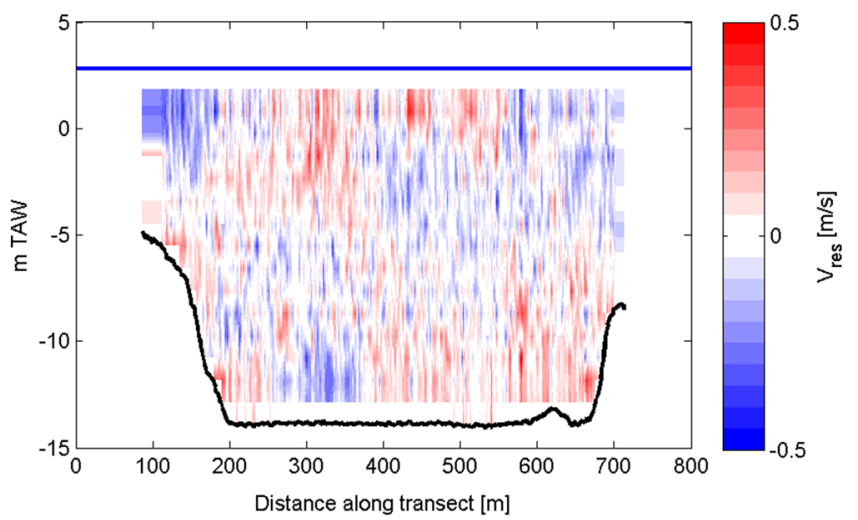

horizontal component is shown top right, the vertical component bottom left, and the residual component bottom right

characterized by large horizontal salinity gradients and the presence of an estuarine turbidity maximum with depthaveraged concentrations ranging from 50 to $500 \mathrm{mg} / \mathrm{l}$ at grain sizes of $60-100 \mu \mathrm{m}$. The salinity gradients generate significant density currents between the river and the entrance channels to the locks, causing large siltation rates (IMDC 2006). During measurement campaigns in the vicinity of Deurganckdok, concentrations larger than $1 \mathrm{~g} / \mathrm{l}$ were seldom found (IMDC 2011). Additional measurements in the Scheldt estuary revealed that a thin fluid mud layer is formed during slack water, which is re-entrained during the following tidal cycle. However, no evidence of thick fluid mud formation near Deurganckdok was found during the extensive measurement campaigns. This therefore suggests that all sediments supplied to Deurganckdok are transported in suspension in the water column (van Maren et al. 2009).

The typical tidal amplitude at Deurganckdok is $5 \mathrm{~m}$. The open water surface is $10^{6} \mathrm{~m}^{2}$, which gives a tidal volume of $5 \times 10^{6} \mathrm{~m}^{3}$. The cross section between the dock and the Scheldt is about $6800 \mathrm{~m}^{2}$.

Over the period 2006-2010, on average, $8 \times 10^{5} \mathrm{TDM} /$ year was dredged in Deurganckdok every year and dumped on authorized dumping sites in the Lower Sea Scheldt. This

number includes maintenance dredging, but excludes capital dredging.

In 2005, a measurement campaign of flow, salinity, and sediment concentration was commissioned by Flanders Hydraulics Research in order to gain insight in the factors contributing to the siltation of Deurganckdok. One of the measurements consisted of 50 sailed transects across the entrance of Deurganckdok, performed over one tidal cycle (an average tide in March 2006). During this campaign, water velocity and sediment concentration were estimated using a 600-kHz Workhorse Acoustic Doppler Current Profiler (ADCP) with a calibrated interpretation of the acoustic backscatter to determine the sediment concentration. This calibration was performed by taking water samples during the measurement campaign (IMDC 2006). One sailed transect is typically $400 \mathrm{~m}$ in length and consists of 70 to 90 ensembles (vertical profiles). Each ensemble has a vertical resolution of $50 \mathrm{~cm}$. Figure 6 shows one transect, measured during flood tide, around the time of high water. Flow velocity (left) and suspended sediment concentration (right) were measured at the same time. For the analysis, the data is resampled on a regular grid of $1 \mathrm{~m} \times 1 \mathrm{~m}$. Sixty-seven percent of the data points in the analysis are derived from measurements; $33 \%$ are filled in through nearest-neighbor extrapolation. 

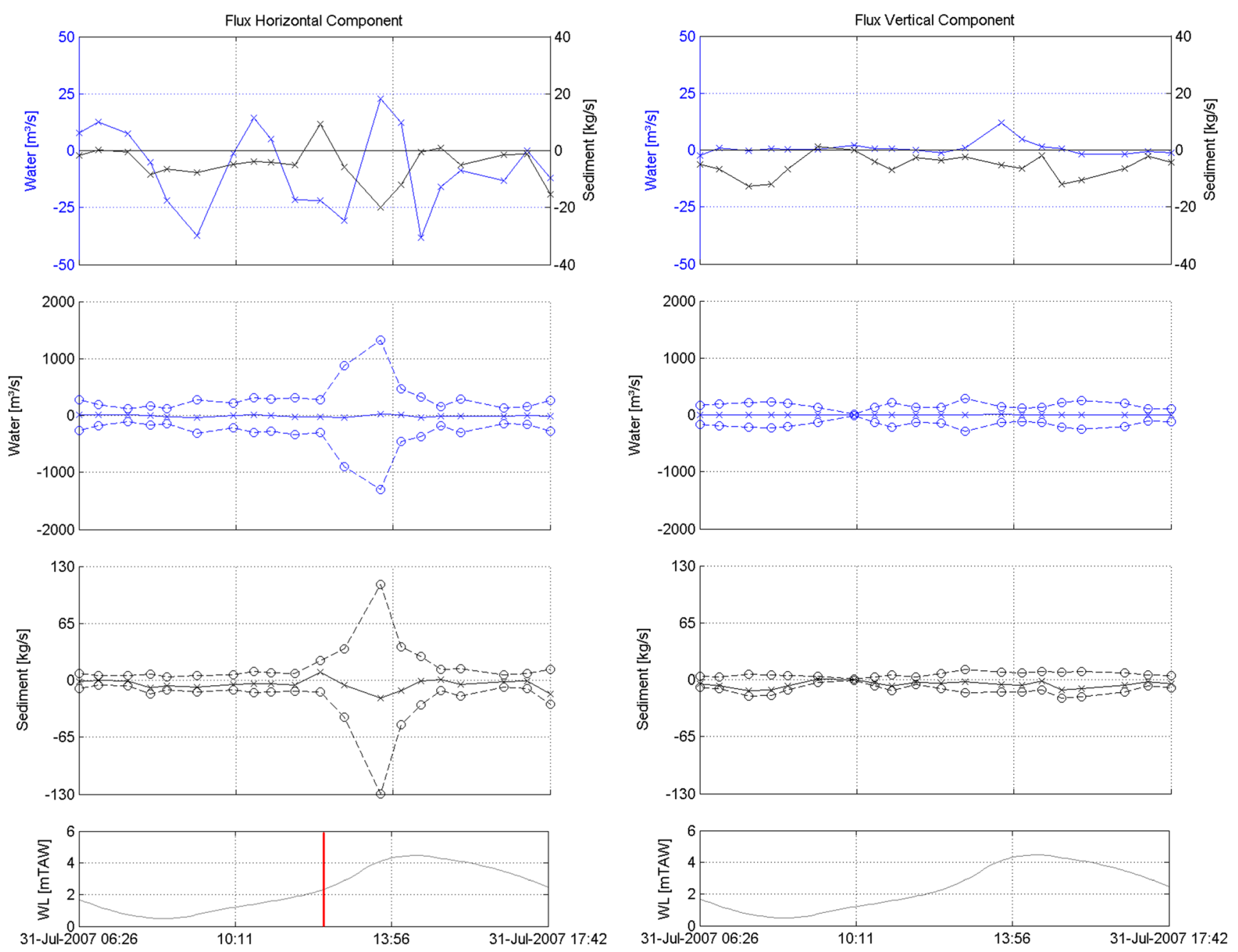

Fig. 5 Results for the Zeebrugge harbor entrance. Horizontal exchange is shown on the left and vertical exchange on the right. Net flux of water (blue) and sediment (black) in the top panel, gross flux (dotted line) and net flux (full line) of water (blue) and sediment (black) in the two middle

\subsection{Results and discussion}

The flow field of Fig. 6 is geometrically decomposed following the method outlined above. The decomposed flow field is presented in Fig. 7.

Table 1 Decomposition of total sediment exchange at the Zeebrugge harbor entrance during one tidal cycle (31 July 2007) into four components and into positive and negative contributions. All values are in TDM; inflow is negative

\begin{tabular}{lllll}
\hline$[\mathrm{TDM}]$ & Net & Gross & Pos & Neg \\
\hline Tidal & -18 & 1805 & 893 & -912 \\
Vertical & -329 & 1127 & 399 & -728 \\
Horizontal & -301 & 2360 & 1030 & -1330 \\
Residual & -59 & 1896 & 918 & -978 \\
Total & -708 & 7190 & 3240 & -3950 \\
\hline
\end{tabular}

panels. Water level is added for reference in the bottom panel. Inflow is negative. The red line indicates the time of the measured transect discussed above

The tidal component around high water is obviously very small. The inflow occurring at the right-hand side of the dock (Fig. 7, top right) indicates that there is still flood flow in the river Scheldt, which drives a primary gyre across the entrance. Note the important vertical exchange (Fig. 7, bottom left).

Following the same method as for the Zeebrugge case, Fig. 8 shows the intratidal variation of the horizontal and the vertical components of the flow and sediment flux.

In general, the net sediment flux is directed inward, indicating a net sedimentation of Deurganckdok. The most notable driver of net sediment import is the vertical component around the time of high water (see right panel in Fig. 8 and the gross figures in Table 2). Whereas the horizontal component of the sediment flux is significant from $4 \mathrm{~h}$ before high water to $1 \mathrm{~h}$ after, it is the vertical component of the sediment flux from half an hour before high water to $2 \mathrm{~h}$ after that has the larger net effect, as seen in Fig. 8. 

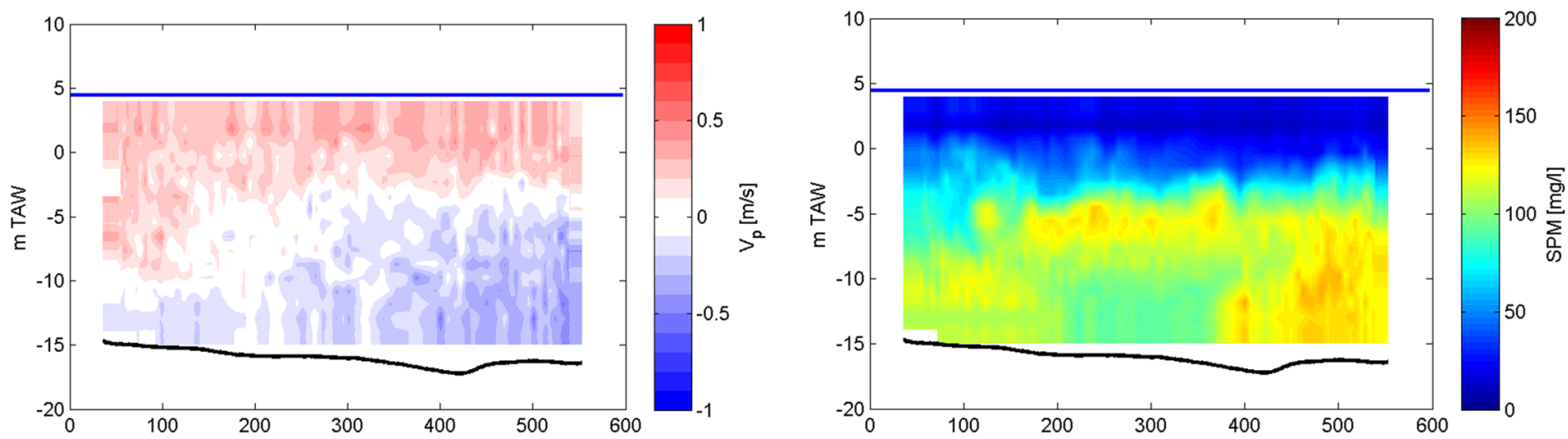

Fig. 6 Measured perpendicular flow (left panel) and suspended sediment concentration (right panel). The measurement was performed at the entrance of Deurganckdok during flood phase

During the measurements in 2006, there was a total net import of $868 \mathrm{t}$ of dry matter (see Table 2). This is well within the range of $1100+/-420 \mathrm{TDM} /$ tide obtained from 3 years of available measurement data (IMDC 2011).

For Deurganckdok, the relative importance of the vertical exchange process is in accordance with the current understanding of the factors contributing to the siltation there. Although the salinity on the Scheldt estuary is vertically uniform, the dock itself is strongly stratified. The horizontal gradient in the Lower Sea Scheldt in front of Deurganckdok, combined with a tidal excursion of the salinity front, yields a
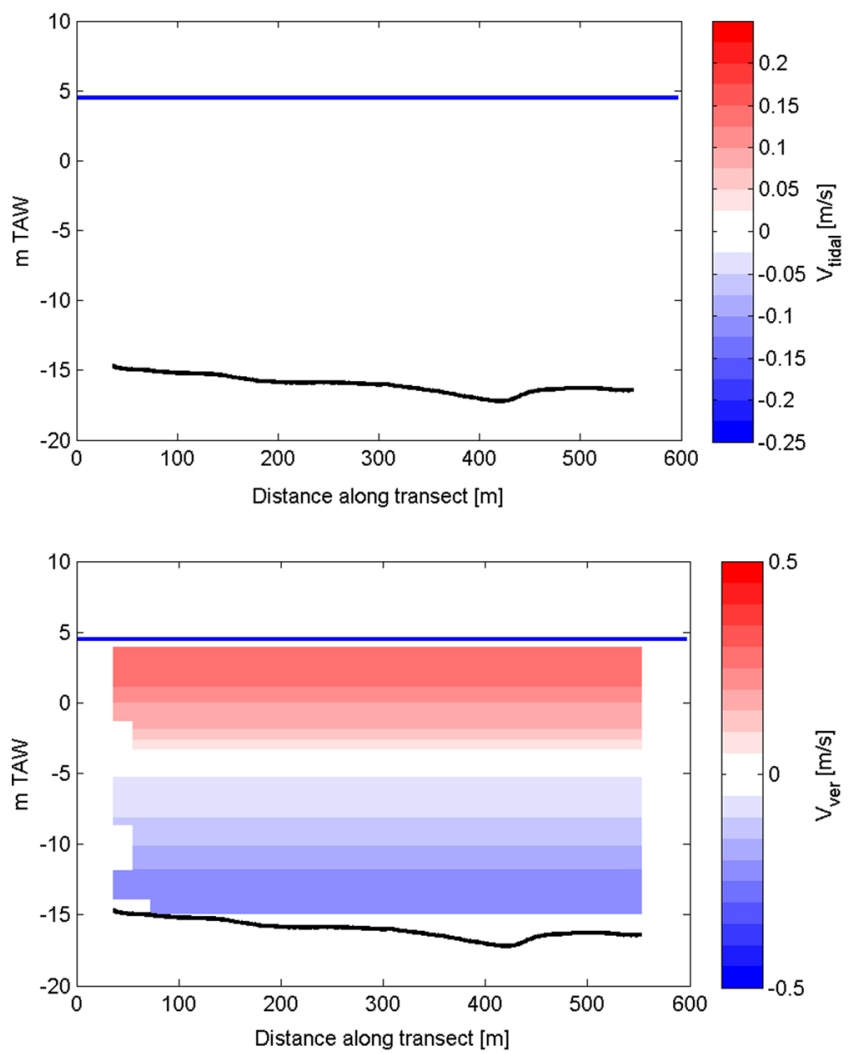

Fig. 7 Result of the geometric decomposition of one measured flow transect at the entrance of Deurganckdok (see Fig. 6). The tidal component (or cross-sectional average) is shown in the top left, the horizontal small tidal salinity variation. Fettweis et al. (1998) found an average tidal salinity amplitude of $4.5 \mathrm{ppt}$ at Prosperpolder, a measurement station downstream of Deurganckdok. The salinity in the dock also has a tidal salinity variation, which lags behind to the salinity in the Scheldt. Thus, a tidally varying density current exists between the Scheldt estuary and the dock that is driven by horizontal gradients (between the river and dock) in the vertical density distribution. When the salinity in the Scheldt estuary is higher than that in the dock, this results in an inflow of saline water into the dock in the lower half of the water column, which is compensated by an outflow
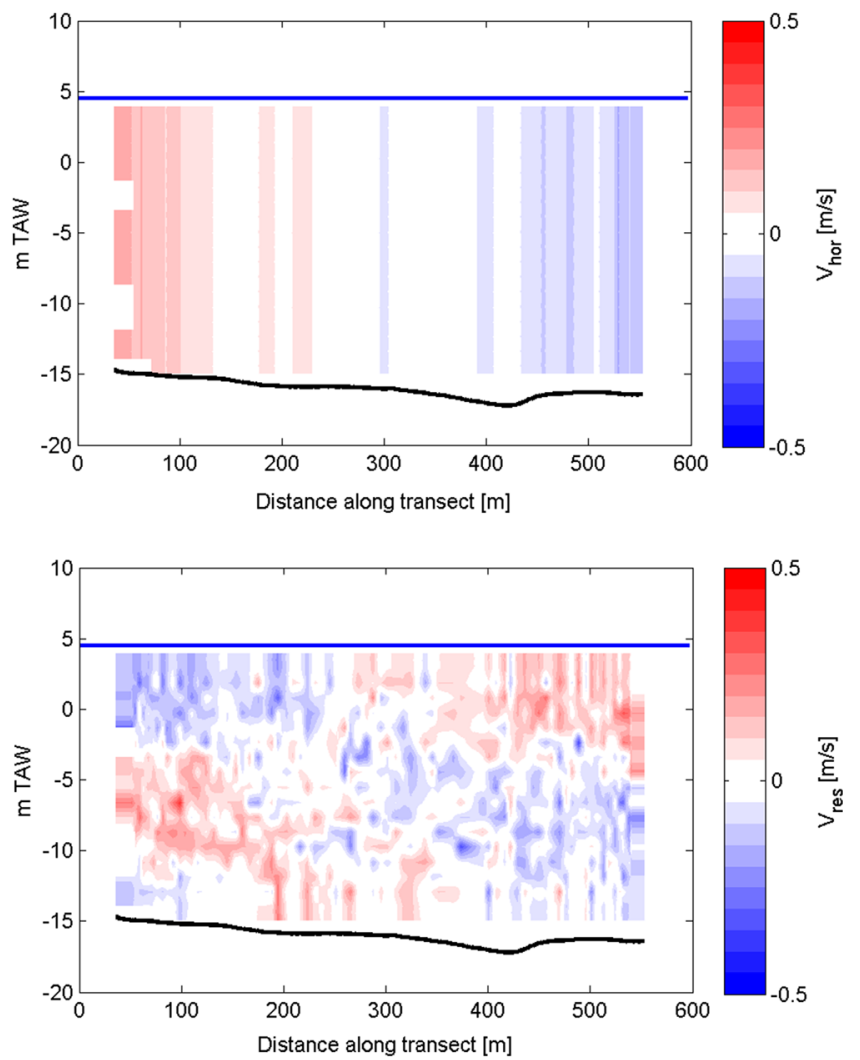

component is shown top right, the vertical component bottom left, and the residual component bottom right 


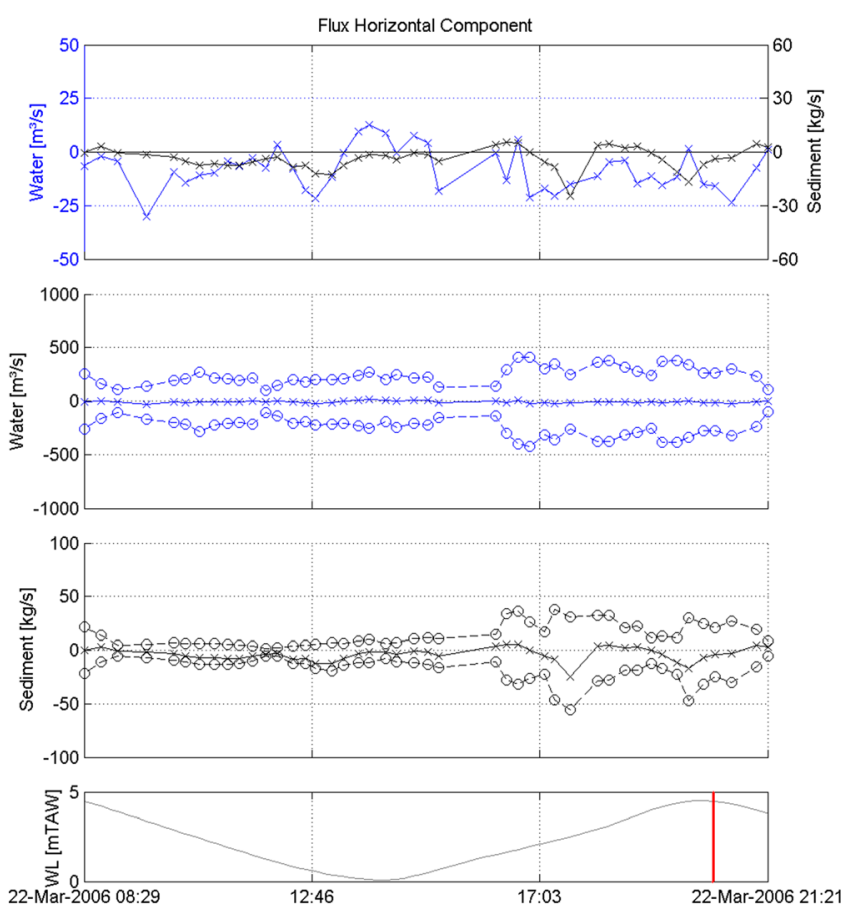

Fig. 8 Results for the Deurganckdok harbor entrance. Horizontal exchange (left) and vertical exchange (right). Net flux of water (blue) and sediment (black) in the top panel. Gross flux (dotted line) and net flux

of less-dense surface water. This occurs typically around high water. This flow pattern is reversed when the salinity in the dock is higher than that in the Scheldt estuary (van Maren et al. 2009). Previous measurement campaigns had already established that the sediment concentration during flood reaches its maximum $0-1 \mathrm{~h}$ before high water. Furthermore, the sediment concentrations during flood are highest on the left bank of the Scheldt estuary, i.e., close to Deurganckdok (IMDC 2005). Thus, the maximum sediment concentrations are present at the time, and the location when and where the salinity-driven density exchange flow is directed into the dock close to the bottom. These established mechanisms are also apparent in the analyzed measurement data, as the right panel in Fig. 8 shows an important net amount of sediment entering

Table 2 Decomposition of total sediment exchange at the Deurganckdok harbor entrance during one tidal cycle (22 March 2006) into four components and into positive and negative contributions. All values are in TDM; inflow is negative

\begin{tabular}{lllll}
\hline$[$ TDM $]$ & Net & Gross & Pos & Neg \\
\hline Tidal & 104 & 452 & 278 & -174 \\
Vertical & -779 & 2298 & 758 & -1540 \\
Horizontal & -192 & 1883 & 843 & -1040 \\
Residual & -2 & 1777 & 888 & -889 \\
Total & -868 & 6410 & 2770 & -3640 \\
\hline
\end{tabular}

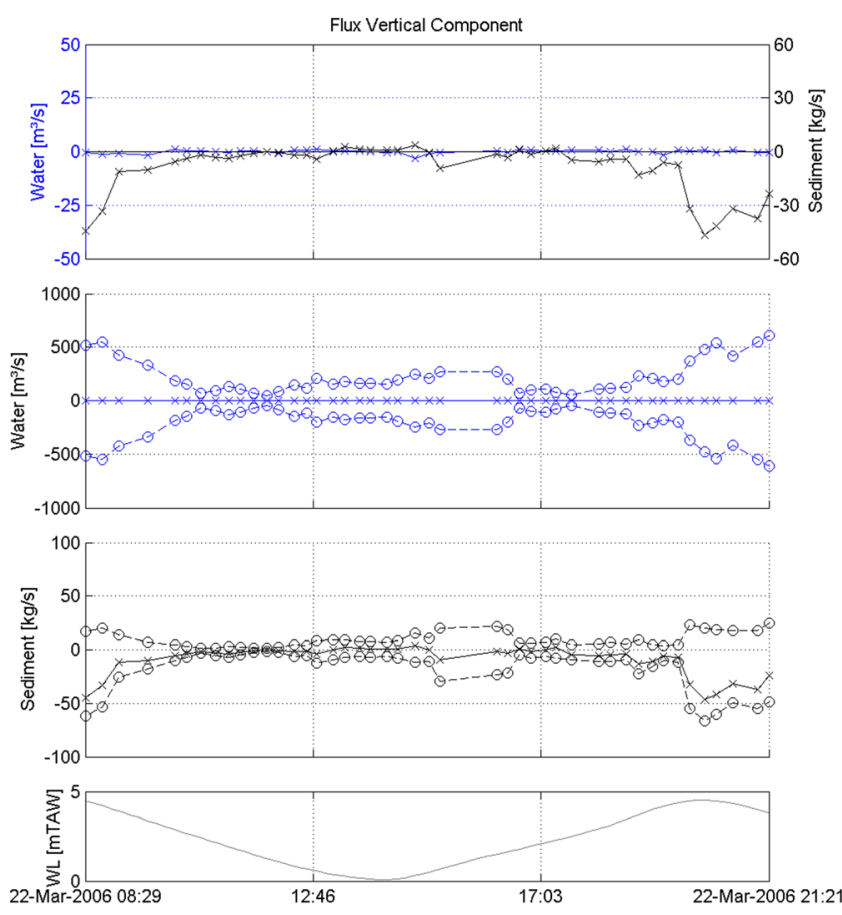

(full line) of water (blue) and sediment (black) in the two middle panels. Water level is added for reference in the bottom panel. Inflow is negative. The red line indicates the time of the measured transect discussed above

the dock through the vertical component around the time of high water.

\subsection{Summary and conclusions}

This paper describes a simple geometric method to decompose the exchange flow of water and sediment between a harbor and the surrounding waters into three main components: the cross-sectional average, horizontal, and vertical exchange flows. The method is applied to measurements at two important harbor basins in Belgium: Zeebrugge (a coastal harbor) and Deurganckdok (a tidal basin in the Scheldt estuary). Both harbor basins are located close to a turbidity maximum, and both require important amounts of maintenance dredging in order to guarantee their nautical accessibility.

When the geometric decomposition is applied to synoptic measurements of flow and sediment flux, differences can be identified in the mechanisms that drive siltation in the two harbor basins. In Deurganckdok, the method picks up on the density-driven vertical exchange flow around high water that is already well described by van Maren et al. (2009). In Zeebrugge, no clear signature is seen in the analyzed measurements of such a density-driven vertical exchange flow. Most of the sediment is exchanged through a clockwise gyre that is being advected into the harbor, just prior to high water. These differences are not directly apparent from the "raw" data of velocity and sediment concentration, but become visible through the geometric decomposition. This 
decomposition can be applied just as well to the results of a 3D numerical model of hydrodynamics and sediment transport, provided it has sufficient horizontal, vertical, and temporal resolutions to capture the dynamics at the harbor mouth. During model calibration and for the interpretation of the results, the modeler may benefit from the techniques that separate the total sediment flux into separate components. This will be elaborated in a separate paper (Vanlede and Page: 16 De Maerschalck, in prep).

In order to understand the relevant processes that govern the net sediment influx (siltation) in a harbor basin, the spatial and temporal cross correlations between the water exchange and the sediment concentration has to be taken into account (de Nijs et al. 2009). By using synoptic observations of hydrodynamics and sediment concentration, this cross correlation is taken into account implicitly.

Nearest-neighbor extrapolation is used to estimate the velocities and sediment concentrations near the ends of the measurement transect, close to the surface and close to the bottom. This is the result of a limitation of the sailed ADCP measurement technique. Around $30 \%$ of the data points used in the analysis are extrapolated, accounting for around $40 \%$ of the estimate of the total gross sediment flux in both applications. The effect of the extrapolation is even more important on the net sediment exchange (with possible sign reversal), partly because the operation of subtracting two large numbers to get a relatively smaller number limits the accuracy with which the net exchange can be calculated. The most important exchange mechanisms are therefore more clearly identified in the gross exchange numbers.

A classification of harbor systems is possible on the basis of the relative importance of the siltation mechanisms, as elaborated by Winterwerp (2005). An insight in the different components of the sediment flux in a harbor can help in the design of siltation-reducing measures. It must be stressed however that the different components are always in complex interaction. Furthermore, care must be taken in the physical interpretation of the results of the geometric analysis. The three main flow mechanisms presented in the introduction have a close proxy in the three main geometric components, but there is no exact match. Consider for instance a case with only tidal filling, following a logarithmic vertical velocity profile. The geometric analysis would result in the decomposition of $v_{n}$ into a cross-sectional average $v_{\text {tidal }}$ and also a small $v_{\mathrm{ver}}$ Special care should therefore be taken when attempting to link a physical explanation to the different geometric components.

Acknowledgments The method presented in this paper was developed within the framework of the project 00059 "accessibility of the harbor of Zeebrugge" at the Flanders Hydraulics Research. This research project was commissioned by the Maritime Access division of the Department Mobility and Public Works of the Flemish government. The first author worked on this paper while affiliated as a guest to Delft University of Technology in the Faculty of Civil Engineering and Geosciences.

The crews of the measurements vessels "Veremans" and "Stream" are acknowledged for their skillful assistance during the measurement campaigns at Deurganckdok and Zeebrugge, respectively. We thank G. Schramkowski, H. Winterwerp, and two anonymous reviewers for their constructive criticism on the earlier drafts of this paper.

Open Access This article is distributed under the terms of the Creative Commons Attribution License which permits any use, distribution, and reproduction in any medium, provided the original author(s) and the source are credited.

\section{References}

Costa, R.C.F.G. (1989) Flow-fine sediment hysteresis in sediment-stratified coastal waters, MS Thesis, University of Florida, Gainesville

de Nijs MAJ, Winterwerp JC, Pietrzak JD (2009) On harbour siltation in the fresh-salt mixing region. Cont Shelf Res 29:175-193

Eysink, W.D. (1989) Sedimentation in harbor basins - small density differences can have serious effects, Proceedings of the 9th international harbour congress, Antwerp, Belgium, June 1988; also: Delft Hydraulics, publication No 417

Fettweis M, Sas M, Monbaliu J (1998) Seasonal, neap-spring and tidal variation of cohesive sediment concentration in the Scheldt estuary, Belgium. Estuar Coast Shelf Sci 46:21-36

Fettweis M, Van den Eynde D (2003) The mud deposits and the high turbidity in the Belgian-Dutch coastal zone. Southern bight of the North Sea. Cont Shelf Res 23:669-691

Fettweis MP, Nechad B (2011) Evaluation of in situ and remote sensing sampling methods for SPM concentrations, Belgian continental shelf (southern North Sea). Ocean Dyn 61:157-171

IMDC (2005) Uitbreiding studie densiteitsstromingen in de Beneden Zeeschelde in het kader van LTV. Meetcampagne naar hooggeconcentreerde slibsuspensies. Deelrapport 2.5: Deurganckdok 16/02/2005. Waterbouwkundig Laboratorium: Antwerpen, België. (In Dutch)

IMDC (2006) Langdurige metingen Deurganckdok: opvolging en analyse aanslibbing. Bestek $16 \mathrm{~EB} / 05 / 04$. Deelrapport 2.3: 13uursmeting springtij - ingang Deurganckdok 22/03/2006. Waterbouwkundig Laboratorium: Antwerpen, België. (In Dutch)

IMDC (2008) Langdurige monitoring van zout/zoet-verdeling in de haven van Zeebrugge en monitoring van zoutconcentratie, slibconcentratie en hooggeconcentreerde slibsuspensies in de Belgische kustzone: deelrapport 7.1. 13-uursmeetcampagne SiltProfiler en Sediview 31/07/2007 Haveningang tijdens springtij. Waterbouwkundig Laboratorium: Antwerpen, België. (In Dutch)

IMDC (2011) Externe effecten Deurganckdok. Deelrapport 1: Syntheserapport van het Current Deflecting Wall Onderzoek. Afdeling Maritieme Toegang: Antwerpen, België. (In Dutch)

Langendoen, E. J. (1992) Flow patterns and transport of dissolved matter in tidal harbours. Dissertation, Delft University of Technology, Department of Civil Engineering

Lauwaert, B. et al. (2008). Synthesis report on the effects of dredged material disposal on the marine environment (licensing period 2006'08). MUMM, ILVO Fisheries, Maritime Access Division, and Coast Division. Ostend, Belgium. 109 pp.

Murray SP, Siripong A (1978) Role of lateral gradients and longitudinal dispersion in the salt balance of a shallow well mixed estuary. Estuarine transport processes. In: Kjerfe BJ, Belle W (eds) Baruch 
library in marine science, $\mathrm{N}^{\circ} 7$. University of South Carolina Press, Columbia

PIANC (2008) Minimising harbour siltation. Report no 102, 75 pp

Stoschek O, Zimmerman C (2006) Water exchange and sedimentation in an estuarine tidal harbor using threedimensional simulation. J Waterw Port Coast Ocean Eng 132(5):410-414
Vanlede J.; De Maerschalck B. (in prep.) Fine-grained sediment transport in the Belgian coastal zone: Data analysis and modeling. Ocean Dyn SI, proceedings Intercoh 2013

van Maren DS, Winterwerp JC, Sas M, Vanlede J (2009) The effect of dock length on harbour siltation. Cont Shelf Res 29:1410-1425

Winterwerp J. C. (2005) Reducing harbor siltation. I: Methodology. J. Waterway, Port, Coastal, and Ocean Eng 